\title{
Validation of Administrative Measures of Social and Behavioral Risk in Veterans Affairs Medical Records
}

\author{
Charlie M. Wray, DO, MS $S^{1,2}$, Marzieh Vali, MS ${ }^{3}$, Ann Abraham, BS ${ }^{3}$, Alysandra Zhang, $B S^{3}$, \\ Louise C. Walter, MD', and Salomeh Keyhani, MD, MPH
}

\begin{abstract}
'Department of Medicine, University of California, San Francisco, San Francisco, CA, USA; ${ }^{2}$ Division of Hospital Medicine, San Francisco Veterans Affairs Medical Center, San Francisco, CA, USA; ${ }^{3}$ Northern California Institute for Research and Education, San Francisco Veterans Affairs Medical Center, San Francisco, CA, USA; ${ }^{4}$ Division of Geriatrics, San Francisco Veterans Affairs Medical Center, San Francisco, CA, USA; 5 Division of General Internal Medicine, San Francisco Veterans Affairs Medical Center, San Francisco, CA, USA.
\end{abstract}

KEY WORDS: social risk factors; health policy; veterans affairs.

J Gen Intern Med 34(6):796-8

DOI: $10.1007 / \mathrm{s} 11606-018-4792-0$

(c) Society of General Internal Medicine 2018

\section{INTRODUCTION}

A growing body of research indicates that social and behavioral risk factors, such as social isolation and marginal housing, influence health outcomes. ${ }^{1}$ Unfortunately, obtaining such risk factors from administrative records remains a challenge. ${ }^{2}$ We assessed the fidelity of administrative coding of six social and behavioral risk factors (lives alone, marginal housing, alcohol and drug abuse, use of substance abuse services, and violence) through chart validation of hospitalized patients within the Veterans Health Administration (VA).

\section{METHODS}

We identified older Veterans ( $\geq 65$ ) who were hospitalized in the VA from 2009 to 2012 with either: congestive heart failure, acute myocardial infarction, or pneumonia. Using national VA data, we created six measures of social and behavioral risk using International Classification of Disease, Ninth Revision (ICD-9) diagnosis codes, VA clinic description codes, and laboratory data (Table 1). After determining the prevalence of each risk factor within our cohort, we randomly identified 50 patient charts that met identification criteria (i.e., contained applicable ICD-9, clinical description codes, or laboratory data) and 50 that did not. Two reviewers independently reviewed all clinical notes in the year prior to discharge from an index admission for evidence of each respective risk factor. A kappa statistic was performed on $25 \%$ of cases for each measure. Positive (PPV) and negative predictive values (NPV) for each risk factor were calculated and recorded.

\section{RESULTS}

Among 600 reviewed charts, "drug abuse" (4.4\%) and "use of substance abuse services" (3.2\%) had the highest prevalence,

Published online January 2, 2019 followed by "living alone" (2.9\%) and "marginal housing" $(2.9 \%)$. Of the six assessed risk factors, patients with administrative measures for "violence" (PPV: 0.94), "alcohol" (PPV: 0.88), and "use of substance abuse services" (PPV: 0.88 ) had the highest PPV. Comparatively, administrative measures for "living alone" (PPV: 0.60) and "marginal housing" (PPV: 0.78) were limited in their predictive abilities. All risk factors except for "lives alone" $(0.72)$ had NPV $>0.85$ (Table 2). The kappa-statistic between pairs of reviewers ranged from 0.66 to 1.0 on a per-measure basis.

\section{DISCUSSION}

In this chart validation of VA administrative diagnostic codes for social and behavioral risk factors known to effect health outcomes, we found excellent PPV for codes specific for "violence," "alcohol abuse," and "use of substance abuse services"-but limited when assessing for "living alone" and "marginal housing." Given the growing understanding of how social risk factors effect health outcomes, ${ }^{3}$ risk-adjustment, ${ }^{4}$ and quality of care, the extent to which such factors can be extracted from administrative data is becoming an increasingly important issue.

A recent study found 22 social characteristics not included in either VA or Medicare's current risk-adjustment methods (e.g., social isolation and smoking status) were predictive of hospital readmissions - suggesting that extraction and inclusion of such factors may be important in risk-adjustment-and by extension, subsequent readmission penalties. ${ }^{4}$ Furthermore, despite the recognized difficulty in obtaining social risk factors from the medical record, the National Quality Forum recently issued a report stating that social risk factors should be included in risk-adjustment models as a means to improve risk adjustment. ${ }^{2}$ Unfortunately, extracting social risk factors from administrative data with adequate validity and efficiency remains a complex endeavor. ${ }^{5}$ Our study may be helpful as we describe a unique extraction approach that is not limited to ICD coding alone, but rather uses a variety of administrative data to assess for the presence of social risk factors. Despite the low prevalence of each risk factor, the use of multiple data 
Table 1 Social and Behavioral Risk Factors Administrative Diagnostic Codes and Definitions used for Chart Review

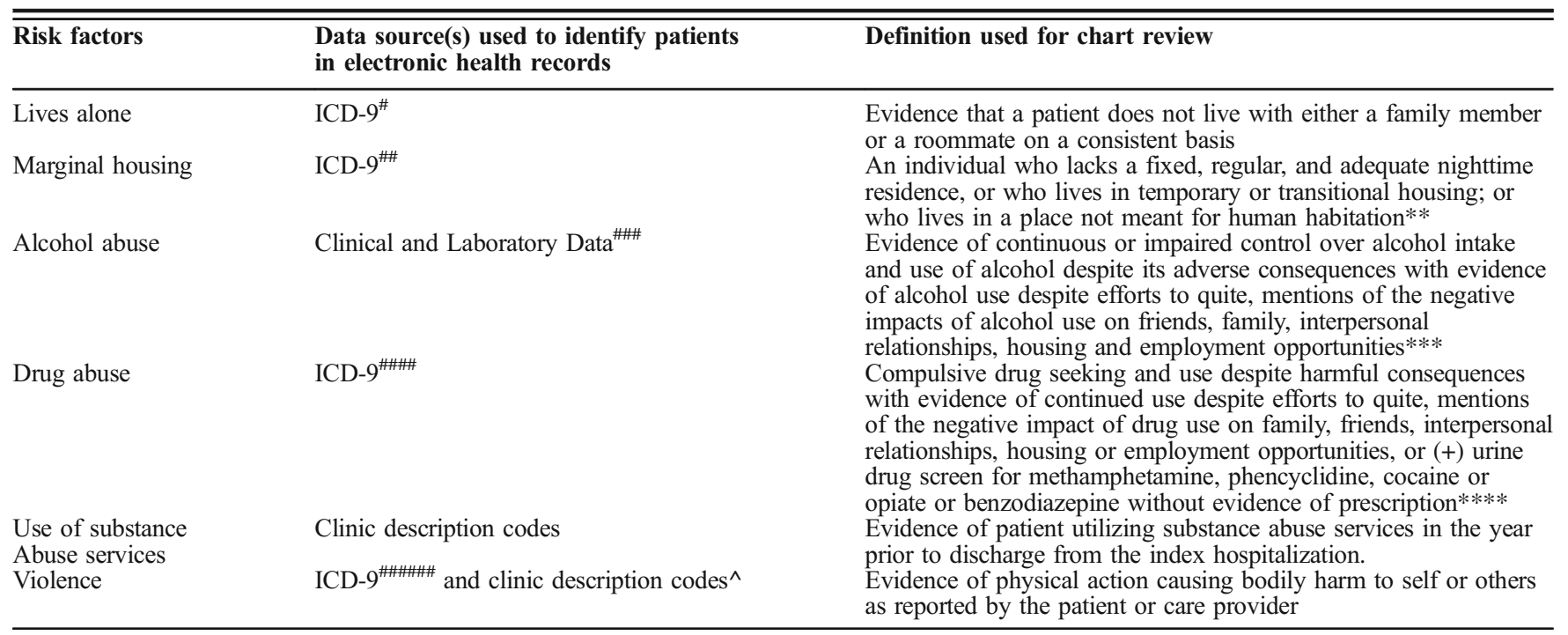

**Adapted from the Housing and Urban Development (HUD) definition for homelessness;

***Adapted from the National Council on Alcoholism and Drug Dependence and the American Society for Addiction Medicine's definitions of alcoholism;

****Adapted from the National Institute of Drug Abuse

ICD-9: Administrative Diagnostic Codes

${ }^{\#}$ ICD-9 Codes: $v 60.3, v 60.4$.

\#ICD-9 Codes: v60.0, v60.1.

\#曲 Logical Observation Identifier Names and Codes (LOINC):

\#\#\# ICD-9 Codes: 965.00, 965.01, 965.02, 965.09, E850.0, E850.1, E850.2, E935.0, E935.1, E935.2, 304.xx, 305.x, 965.0x, 967.0, 969.4, 969.6, 969.7, E850.0, E850.1, E850.2, E854.1, E854.2, E854.3.

\#\#\#\#看 Clinic Description Codes: 513, 514, 519, 545, 547, 548, 560, 593, 595, 596, 597, 598, 599.

\#\#\#\#\#ICD-9 Codes: E985.x, E986, E960.x, E962.0, E962.1, E962.2, E963, E965.x, E966, E967.x, E968.x, E970, E971, E972, E973, E974, E975, E976, E977

${ }^{\wedge}$ VA Clinic Description Codes: 130, 131

sources likely contributed to the favorable performance of the administrative measures.

Our study has limitations. First, because a natural ambiguity of some social risk factors (e.g., marginal housing, and violence) exists, this may lead to under-coding, thus missing patients who may be affected by these risk factors. Second, given the specificity of our cohort to older hospitalized patients, generalizability to other populations may be limited. Finally, we were restricted to the use of ICD-9 diagnostic codes given the time-span of our cohort.

Table 2 Chart Validation Characteristics for Social and Behavioral Risk Factors

\begin{tabular}{|c|c|c|c|}
\hline $\begin{array}{l}\text { Social risk } \\
\text { factor }\end{array}$ & $\begin{array}{l}\text { No. }(\%) \text { of } \\
\text { patients } \\
\text { identified in } \\
\text { EHR }\end{array}$ & $\begin{array}{l}\text { Positive } \\
\text { predictive } \\
\text { value }\end{array}$ & $\begin{array}{l}\text { Negative } \\
\text { predictive } \\
\text { value }\end{array}$ \\
\hline Lives alone & $3472(2.9 \%)$ & 0.60 & 0.72 \\
\hline $\begin{array}{l}\text { Marginal } \\
\text { housing }\end{array}$ & $3509(2.9 \%)$ & 0.78 & 0.94 \\
\hline $\begin{array}{l}\text { Use of } \\
\text { substance } \\
\text { abuse services }\end{array}$ & $3925(3.2 \%)$ & 0.88 & 1.0 \\
\hline Alcohol abuse & $2874(2.4 \%)$ & 0.88 & 0.86 \\
\hline Drug abuse & $5325(4.4)$ & 0.82 & 1.0 \\
\hline Violence & $136(0.11 \%)$ & 0.94 & 0.96 \\
\hline
\end{tabular}

EHR, Electronic Health Record
In total, this study indicates that VA administrative codes for social and behavioral risk factors such as violence, alcohol and drug abuse, and use of substance abuse services are accurate indicators of the presence of these risk factors. Further work in assessing other social and behavioral risk factors that may affect health outcomes is needed and will assist in optimizing care for at-risk individuals.

Corresponding Author: Charlie M. Wray, DO, MS; Division of Hospital Medicine San Francisco Veterans Affairs Medical Center, Clement Street, San Francisco, CA, USA (e-mail: Charlie.Wray@ucsf. edu).

\section{Compliance with Ethical Standards:}

Conflict of Interest: The authors declare that they have no conflict of interest.

Publisher's Note: Springer Nature remains neutral with regard to jurisdictional claims in published maps and institutional affiliations.

\section{REFERENCES}

1. NQF: Risk Adjustment for Socioeconomic Status or Other Sociodemographic Factors. http://www.qualityforum.org/Publications/ 2014/08/Risk_Adjustment_for_Socioeconomic_Status_or_Other_ Sociodemographic_Factors.aspx. Accessed October 31, 2018.

2. Steventon A. Making the best use of administrative data. BMJ 2013;346:f1284. https://doi.org/10.1136/bmj.f1284 
3. Determinants of Health and Longevity Agency for Healthcare Research \& Quality. https://www.ahrq.gov/professionals/education/curriculumtools/population-health/adler.html Published September 15, 2015. Accessed October 31, 2018.

4. Barnett ML, Hsu J, McWilliams JM. Patient characteristics and differences in hospital readmission rates. JAMA Intern Med.
2015;175(11):1803-1812. https://doi.org/10.1001/jamainternmed.2015. 4660

5. Gottlieb L, Tobey R, Cantor J, Hessler D, Adler NE. Integrating social and medical data to improve population health: opportunities and barriers. Health Aff (Millwood). 2016;35(11):2116-2123. https://doi.org/10.1377/ hlthaff.2016.0723 